\title{
A Cross-Sectional Survey; Knowledge, Attitudes, and Practices of Self-Medication in Medical and Pharmacy Students
}

Razan Alduraibi ( $\sim 391202599 @ q u . e d u . s a)$

Qassim University

\section{Waleed Altowayan}

Department of Pharmacy Practice, College of pharmacy, Qassim university, Qassim

\section{Research Article}

Keywords: knowledge, Self-medication, Medical Student, Qassim university

Posted Date: November 30th, 2021

DOI: https://doi.org/10.21203/rs.3.rs-1053208/v1

License: (c) (1) This work is licensed under a Creative Commons Attribution 4.0 International License.

Read Full License

Version of Record: A version of this preprint was published at BMC Health Services Research on March 17th, 2022. See the published version at https://doi.org/10.1186/s12913-022-07704-0. 


\section{Abstract}

Background: Self-Medication is common practice worldwide in both developed and developing countries. Self-Medication is referred as self consumption of medication without consulting a physician for either diagnosis or treatment. This study aimed to assess the knowledge, attitudes and practices toward selfmedication among medical and pharmacy students.

Methods: This cross-sectional study was conducted among medical and pharmacy students in Qassim university, Buraydah, Saudi Arabia, during the period 2020-2021.Multistage random sampling technique was used to recruit students. The data were collected through questionnaire.

Results: Three hundred and sixteen of 316 students were recruited. This study showed that the majority $(94.6 \%)$ of students had good knowledge of self-medication. Additionally, the following characteristics were significantly associated with good knowledge: being female, and Pharmacy students. Overall mean score for the attitudes towards self-medication shows that $58.4 \%$ of the total sample had high agreements towards the questions of the attitudes toward self-medication. More than half $(63.9 \%)$ of the students reported that they practice self- medication in the last 6 months. Pain killers was the most common medication used for self- medication by the majority of the students (88.29\%).

Conclusions: In conclusion, students' knowledge of self-medication appears to be good and significantly high among pharmacy students in comparison to medical students. As well self-medication was highly practiced among the students. Therefor, medical and pharmacy students should be viewed as important contributors to the public health care system, and future health professionals should be properly educated on good pharmacy practice and responsible self-medication.

\section{Trial registration}

Not applicable

\section{Background}

Self-medication (SM) is a common practice in both developed and developing countries worldwide. SM is referred to as self-consumption of medication without consulting a physician for either diagnosis or treatment. The World Health Organization (WHO) defines SM practice as "use of over-the-counter medication (OTC) to treat self-diagnosed symptoms or disorders, or for the continuation and reuse of prescribed medications for recurrent diseases" ${ }^{1}$. SM has various forms, including taking medications without a physician's prescription, using a previous prescription for a similar condition, or using drugs obtainable at home without getting a physician's advice. SM can be a serious issue and can lead to several problems, such as negative pharmaceutical reactions, a possible increase in antimicrobial resistance, and can be a waste of resources ${ }^{2}$. 
The most prominent causes encouraging SM in Saudi Arabia and across the world are previous disease experience, insufficient information about diseases, economic problems, insufficient time to visit a physician, and easy access to drugs ${ }^{3,4}$.

$\mathrm{SM}$ was found to be on the rise in prior surveys released from various countries. For example, in Bangladesh, Jordan, Egypt and Ethiopia, the prevalence of SM was $88 \%, 86.7 \%, 52.7 \%, 32.7 \%$, and $70.8 \%$, respectively ${ }^{5-9}$.

In Saudi Arabia, high prevalence percentages of $98.7 \%, 86.6 \%, 81,69 \%, 64.8 \%$, and $19.61 \%$ have been found in a few studies that have been conducted to report SM prevalence among university students. 3,10-13 Two of these studies were carried out at Qassim University 10,13 .

Medical and pharmacy students are generally different from other university students, as they are exposed to knowledge about diseases and drugs, which makes SM easier for them to practice. Therefore, pharmacists and physicians have an important role in providing useful recommendations on the proper and safe usage of pharmaceutical drugs. To the best of our knowledge, no study has focused on investigating the knowledge, attitudes, and practices of medical and pharmacy students toward SM in the Qassim region. Therefore, our objective was to assess the knowledge, attitude, and SM practices of medical and pharmacy students at Qassim University and to examine the association between demographic characteristics, knowledge and attitudes.

\section{Methods}

\section{Study setting}

A cross-sectional study was conducted using a questionnaire among medical and pharmacy students in Qassim University, Buraydah, Saudi Arabia, during the 2020-2021 period.

A multistage random sampling technique was used to choose the respective number of students. Medical and Pharmacy Colleges, plus entry years were considered strata. Students were randomly selected from each stratum. All medical and pharmacy students from year one to year four were included. Medical and pharmacy students were excluded if they were not available during the study period or refused to participate.

\section{Sample size}

The sample size was calculated by using a standard sample size equation "n=z2p(1-p)/e2" and a proportion of $50 \%$ (the assumed proportion of students who had good knowledge of and attitudes toward SM). Using a $95 \%$ confidence interval and a $5 \%$ margin of error, the sample size was estimated to be 285 and was adjusted to 342 to compensate for the nonresponse rate.

\section{Validity and reliability}


The questionnaire was developed by the principal investigator based on the study objectives and after a literature review of similar studies. A panel of 3 physicians, all of whom provided clinical care for patients familiar with the survey's development, assessed the questionnaire for appropriateness, accuracy, and relevance, plus were asked to critique the questionnaire's content. To ensure the face validity of the questionnaire, it was presented to a sample of 20 students on two occasions. These students were chosen from medical and pharmacy faculties and were from different academic years. The results of the piloted questionnaires were not included in the analysis. To estimate the internal consistency of the items, a reliability scale evaluation was performed. A good Cronbach's alpha $(a=0.75)$ score was achieved.

As the research was conducted during the COVID-19 pandemic, students were asked to join a Zoom meeting conducted by the investigators to enforce social distancing. The aims of the study were explained to the students, and they were asked for consent. A standard pretested questionnaire was prepared using Google forms and emailed to 342 students after receiving their consent. Two reminder emails were sent after an interval of 1 month.

The questionnaire was divided into four sections with a total of 33 questions. The first section pertained to demographic characteristics, including age, gender, level of education, and nationality. The second section assessed the students' knowledge regarding SM. The response choices for knowledge items included "yes", "no" and "do not know". Correct answers were scored as 1, while incorrect answers and "do not know" were scored as 0 . The total knowledge score ranged from 0 to 7 (7 items). Knowledge was defined as poor for a score of $0-4$ and good for a score of 5-7.

The third section assessed the attitudes of students toward SM. Five-point Likert scale items were used; strongly agree responses were scored as 5 , agree as 4 , uncertain as 3 , disagree as 2 , and strongly disagree as 1.The fourth section assessed the SM practices of students. Questions were asked about the types of drugs used and ailments experienced by the students, as well as their reasons for and the negative outcomes of self-medication.

\section{Data management and analysis plan}

The data collected through Google Form were recoded and entered using the Statistical Package SPSS (v.26), to describe the basic features of the data in the study through frequencies and percentages.

Spearman's rho test was used to test the relation between knowledge and attitudes toward SM, since both were assessed using ordinal values. Chi-squared test $\left(\chi_{2}\right)$ was used to find the association between the level of knowledge (poor - good) and sociodemographic variables. Finally, ANOVA was used to find the differences in the mean attitude scores of the 5-Likert scale according to sociodemographic variables.

\section{Ethical approval}

Approval for the study was obtained from the Institutional Review Board, College of Medicine, Qassim University (no. 20-07-03), Qassim, Saudi Arabia. Each participant received the questionnaire and was 
informed about the objective of the present study. All participants provided an informed google consent form. The Institutional Review Board has agreed that completing the questionnaire will imply consent.

\section{Results}

\section{Demographic information}

Three hundred and sixteen of the 343 , students completed the questionnaires (response rate of $92 \%$ ).

Table 1 shows that the total sample size was $316 ; 54.4 \%$ were female, and $45.6 \%$ were male. The most common age group was $21-23$ years, accounting for $68.7 \%$ of the total sample, while $83.5 \%$ lived in urban areas and $16.5 \%$ lived in rural areas. Regarding specialty, $50.3 \%$ studied medicine and $49.7 \%$ pharmacy. Regarding education level, the highest percentage was $34.5 \%$ for first year students. It was seen that $86.1 \%$ did not have health insurance, and $88.3 \%$ reported having no medical illness.

Table 1. Demographic characteristics of the students $(n=316)$

\begin{tabular}{|c|c|c|c|}
\hline & Groups & $\mathrm{N}$ & $\%$ \\
\hline \multirow[t]{2}{*}{ Gender } & Male & 144 & 45.6 \\
\hline & Female & 172 & 54.4 \\
\hline \multirow[t]{3}{*}{ Age } & $18-20$ & 60 & 19.0 \\
\hline & $21-23$ & 217 & 68.7 \\
\hline & $24-27$ & 39 & 12.3 \\
\hline \multirow[t]{2}{*}{ Area of living } & Urban & 264 & 83.5 \\
\hline & Rural & 52 & 16.5 \\
\hline \multirow[t]{2}{*}{ Specialty } & Medicine & 159 & 50.3 \\
\hline & Pharmacy & 157 & 49.7 \\
\hline \multirow[t]{4}{*}{ Education level } & First year & 109 & 34.5 \\
\hline & Second year & 52 & 16.5 \\
\hline & Third year & 83 & 26.3 \\
\hline & Fourth year & 72 & 22.8 \\
\hline \multirow[t]{2}{*}{ Do you have health insurance? } & Yes & 44 & 13.9 \\
\hline & No & 272 & 86.1 \\
\hline \multirow[t]{2}{*}{ Do you have any medical illness? } & Yes & 37 & 11.7 \\
\hline & No & 279 & 88.3 \\
\hline
\end{tabular}




\section{Students' knowledge of self-medication}

More than half (81.6\%) of students had adequate knowledge that SM is defined as self-consuming medication without receiving advice from a physician. Moreover, the majority (94.3\%) of students knew that all medications (prescription, OTC and herbal) had adverse effects. Most of them (94.9\%) recognized the importance of seeking physician help in case of adverse drug effects. A total of $308(97.5 \%)$ students were aware that using medications with unknown substances in patients with liver and kidney disease is dangerous, and nearly all students knew that increasing or decreasing medication doses without a doctor consultation can be dangerous. More than half (88.3\%) of students knew that SM can mask signs and symptoms of some diseases (Table 2).

The total knowledge scores ranged between 0 and 7; a poor level was considered for a total score of 0,1 , 2,3 or 4 out of 7, and a good level was considered for a total score of 5, 6 and 7 out of 7 . The results show that 17 out of 316 students, which represent $5.4 \%$ of the total sample, had poor knowledge of SM, indicating total scores lower than 5, while the other 299 students, which represent $94.6 \%$ of the sample, had good knowledge of SM, indicating total scores of 5 and above.

Table 2. Self-medication knowledge of Medical and Pharmacy students $(n=316)$ 


\begin{tabular}{|c|c|c|c|}
\hline Question & & $\mathrm{n}$ & $\%$ \\
\hline \multirow{3}{*}{$\begin{array}{l}\text { 1-SM is defined as self-consuming of medication without getting advice } \\
\text { from a physician. }\end{array}$} & Yes* & 258 & 81.6 \\
\hline & No & 32 & 10.1 \\
\hline & $\begin{array}{l}\text { I don't } \\
\text { know }\end{array}$ & 26 & 8.2 \\
\hline \multirow[t]{3}{*}{ 2- SM is safe? } & Yes & 72 & 22.8 \\
\hline & No* & 197 & 62.3 \\
\hline & $\begin{array}{l}\text { I don't } \\
\text { know }\end{array}$ & 47 & 14.9 \\
\hline \multirow[t]{3}{*}{ 3- All medications (prescription, OTC and herbal) have adverse effects? } & Yes* $^{*}$ & 298 & 94.3 \\
\hline & No & 13 & 4.1 \\
\hline & $\begin{array}{l}\text { I don't } \\
\text { know }\end{array}$ & 5 & 1.6 \\
\hline \multirow{3}{*}{$\begin{array}{l}\text { 4- Increasing or decreasing medication dose without a doctor consultation } \\
\text { can be dangerous? }\end{array}$} & Yes* & 307 & 97.2 \\
\hline & No & 5 & 1.6 \\
\hline & $\begin{array}{l}\text { I don't } \\
\text { know }\end{array}$ & 4 & 1.3 \\
\hline \multirow[t]{3}{*}{ 5- In case of adverse effects, physician help must be sought. } & Yes* & 300 & 94.9 \\
\hline & No & 1 & 0.3 \\
\hline & $\begin{array}{l}\text { I don't } \\
\text { know }\end{array}$ & 15 & 4.7 \\
\hline \multirow{3}{*}{$\begin{array}{l}\text { 6- Using medications with unknown substances in patients with liver and } \\
\text { kidney disease is dangerous. }\end{array}$} & Yes* & 308 & 97.5 \\
\hline & No & 3 & 0.9 \\
\hline & $\begin{array}{l}\text { I don't } \\
\text { know }\end{array}$ & 5 & 1.6 \\
\hline \multirow[t]{3}{*}{ 7- SM can mask signs and symptoms of some disease? } & Yes* & 279 & 88.3 \\
\hline & No & 7 & 2.2 \\
\hline & $\begin{array}{l}\text { I don't } \\
\text { know }\end{array}$ & 30 & 9.5 \\
\hline Poor knowledge & & 17 & 5.4 \\
\hline Good knowledge & & 299 & 94.6 \\
\hline
\end{tabular}

*: Choose answer which you consider a good response 
Table 3 demonstrates a statistically significant association $(P<.05)$ between good knowledge and the following student characteristics: being female and pharmacy students.

Table 3. Association between knowledge and demographic variables $(n=316)$

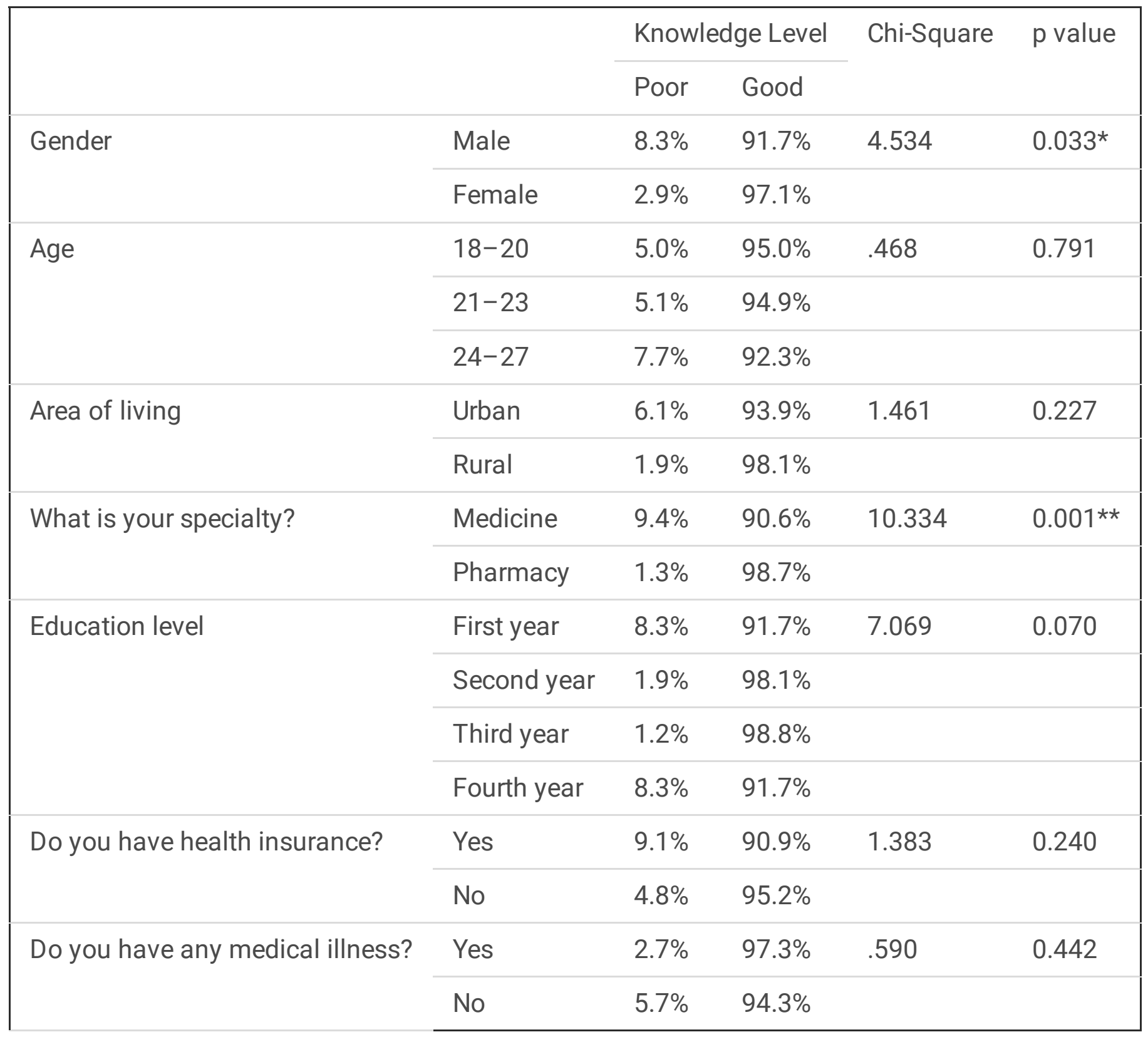

*significant at $p<.05$

\section{Students' attitudes toward self-medication}

Table 4 shows the students' responses to the seven questions on attitudes toward SM. The highest mean score was 3.49 out of the 5-point scale for (The availability of OTC medicines and the belief on its safety leading me to use SM), followed by mean score 3.29 for (Easy access to health care information and facilities, the main cause that medical and pharmacy student use self- medication). The lowest mean score of agreement was 1.98 out of 5 (no need for training to use SM?). The overall mean score for 
attitudes toward SM was 2.92 out of the 5 scales, with an SD of 0.692 , which represents approximately $58.4 \%$ of the total sample, and has high agreement with the questions on attitudes toward SM at Qassim University, Saudi Arabia.

Table 4. Medical and Pharmacy students' attitudes toward self-medication $(n=316)$

\begin{tabular}{|c|c|c|c|c|c|}
\hline Question & $\mathrm{N}$ & Minimum & Maximum & Mean & $\begin{array}{l}\text { Std. } \\
\text { Deviation }\end{array}$ \\
\hline 1-Self-medication part of self care. & 316 & 1 & 5 & 3.10 & 1.309 \\
\hline $\begin{array}{l}\text { 2- No need for training to use self- } \\
\text { medication? }\end{array}$ & 316 & 1 & 5 & 1.98 & 1.238 \\
\hline $\begin{array}{l}\text { 3- Medical and pharmacy students are able to } \\
\text { diagnose different diseases. }\end{array}$ & 316 & 1 & 5 & 3.12 & 1.176 \\
\hline $\begin{array}{l}\text { 4- Medical and pharmacy students are able to } \\
\text { treat different diseases. }\end{array}$ & 316 & 1 & 5 & 2.98 & 1.268 \\
\hline $\begin{array}{l}\text { 5- Do you recommend self medication to } \\
\text { others? }\end{array}$ & 316 & 1 & 5 & 2.48 & 1.268 \\
\hline $\begin{array}{l}\text { 6- Easy access to health care information and } \\
\text { facilities, the main cause that medical and } \\
\text { pharmacy student use self- medication. }\end{array}$ & 316 & 1 & 5 & 3.29 & 1.183 \\
\hline $\begin{array}{l}\text { 7- The availability of OTC medicines and the } \\
\text { belief of its safety leading me to use SM. }\end{array}$ & 316 & 1 & 5 & 3.49 & 1.256 \\
\hline Attitude & 316 & 1 & 5 & 2.92 & 0.691 \\
\hline
\end{tabular}

Table 5 demonstrates a statistically significant difference $(P<.05)$ in the mean attitude score and the following student characteristics: being male, being 21-23 years old, and being pharmacy students.

A statistically significant negative relation between knowledge and the self-medication part of self-care $(r=-0.152, p<0.05)$. The higher the knowledge of SM, the lower the believe in the SM part of self care. In addition, there was a statistically significant negative relation between knowledge and recommendation of SM to others $(r=-0.143, p<0.05)$. Hence, the higher the good knowledge of $S M$, the lower the recommendation of SM to others.

Table 5. Association between knowledge score and attitudes score $(n=316)$ 


\begin{tabular}{|c|c|c|c|c|}
\hline \multirow[b]{2}{*}{ 1-Self-medication part of self care. } & \multirow{2}{*}{$\begin{array}{l}\text { Spearman's } \\
\text { rho } \\
-0.152\end{array}$} & \multirow{2}{*}{$\begin{array}{r}\begin{array}{r}P \\
\text { value }\end{array} \\
0.007\end{array}$} & \multicolumn{2}{|c|}{ Significance } \\
\hline & & & $<0.001$ & $S$ \\
\hline 2- No need for training to use self- medication? & -0.087 & 0.123 & $>0.05$ & N.S. \\
\hline & -0.063 & 0.264 & $>0.05$ & N.S. \\
\hline \multicolumn{5}{|l|}{$\begin{array}{l}\text { 3- Medical and pharmacy students are able to diagnose } \\
\text { different diseases. }\end{array}$} \\
\hline $\begin{array}{l}\text { 4- Medical and pharmacy students are able to treat } \\
\text { different diseases. }\end{array}$ & -0.089 & 0.115 & $>0.05$ & N.S. \\
\hline 5- Do you recommend self medication to others? & -0.134 & 0.017 & $<0.05$ & $S$ \\
\hline $\begin{array}{l}\text { 6- Easy access to health care information and facilities, the } \\
\text { main cause that medical and pharmacy student use self- } \\
\text { medication. }\end{array}$ & 0.129 & 0.022 & $<0.05$ & $S$ \\
\hline $\begin{array}{l}\text { 7- The availability of OTC medicines and belief of its safety } \\
\text { leading me to use SM. }\end{array}$ & 0.082 & 0.148 & $>0.05$ & N.S. \\
\hline Attitude & -0.093 & 0.097 & $<0.10$ & $S$ \\
\hline
\end{tabular}

\section{Students' practices toward self-medication}

The students' practice towards the statements about SM is illustrated in Table 6. More than half (63.9\%) of the students reported that they had practiced SM in the last 6 months. The majority $(79.1 \%)$ of respondents knew the medication classification of OTCs and prescription drugs. Pain killers were the most common medication used for SM by the majority of the students $(88.29 \%)$, followed by antipyretics (49.68\%). It was also observed that $36.71 \%$ of the students reported having self-medicated with antihistamine; others are listed in Table 6.

Table 6. Students' practices toward self-medication $(n=316)$ 
Question

n $\%$

$202 \quad 63.9$

$114 \quad 36.1$

1- Did you practice SM in the last 6 months?

2- How frequently did you visit the pharmacy to purchase drugs without a prescription for yourself in the last 6 Months?

Yes

No

Once

Twice

Three times

Four times

Five times

More than five times

3- Do you know if the medicines you consumed needed prescription or not?

4- Which of the following drugs have you taken without prescription during the last 6 months?
5- For which of the following indications have you taken medications without prescription during the last 6 months?
$153 \quad 48.4$

$65 \quad 20.6$

$60 \quad 19.0$

$16 \quad 5.1$

$3 \quad 0.9$

$19 \quad 6.0$

$250 \quad 79.1$

$33 \quad 10.4$

$33 \quad 10.4$

$279 \quad 88.29$

$110 \quad 34.81$

$\begin{array}{lll}\text { Antibiotics } & 110 \quad 34.81\end{array}$

$\begin{array}{lll}\text { antipyretics } & 157 \quad 49.68\end{array}$

$\begin{array}{lll}\text { Antihistamines } & 116 \quad 36.71\end{array}$

\begin{tabular}{|lcc|}
\hline Cough syrups & 42 & 13.29 \\
\hline $\begin{array}{l}\text { Cold and flu } \\
\text { preparations }\end{array}$ & 59 & 18.67 \\
\hline
\end{tabular}

$\begin{array}{lll}\text { Antacid drugs } & 30 \quad 9.49\end{array}$

Drugs for constipation $\quad 42 \quad 13.29$

\begin{tabular}{lll}
\hline Drugs for diarrhea & 9 & 2.85 \\
\hline Anti-emetics & 12 & 3.8 \\
\hline Nasal/Ear/Eye drops & 100 & 31.65 \\
\hline $\begin{array}{l}\text { Topical agents (skin } \\
\text { treatment }\end{array}$ & 96 & 30.38 \\
\hline $\begin{array}{l}\text { Nutritional/energy } \\
\text { supplements }\end{array}$ & 92 & 29.11 \\
\hline Herbs & 69 & 21.84
\end{tabular}

I do not take $199 \quad 62.97$

Headache

$204 \quad 64.56$




\begin{tabular}{|c|c|c|}
\hline Cough \& common cold & 110 & 34.81 \\
\hline Fever & 98 & 31.01 \\
\hline Infection & 22 & 6.96 \\
\hline Heart burn & 23 & 7.28 \\
\hline Allergy & 47 & 14.87 \\
\hline $\begin{array}{l}\text { Disorder of digestive } \\
\text { system }\end{array}$ & 37 & 11.71 \\
\hline Body pain & 66 & 20.89 \\
\hline Tooth pain & 41 & 12.97 \\
\hline Acne/skin diseases & 90 & 28.48 \\
\hline Menstrual problems & 78 & 24.68 \\
\hline Insomnia & 22 & 6.96 \\
\hline Relatives & 68 & 21.52 \\
\hline Friends & 32 & 10.13 \\
\hline Personal knowledge & 205 & 64.87 \\
\hline Multi media & 84 & 26.58 \\
\hline $\begin{array}{l}\text { Advised by Doctors but } \\
\text { without prescription }\end{array}$ & 114 & 36.08 \\
\hline $\begin{array}{l}\text { Pharmacists or those } \\
\text { working in the } \\
\text { pharmacy }\end{array}$ & 160 & 50.63 \\
\hline Name of the drug & 275 & 87.03 \\
\hline Indication & 237 & 75 \\
\hline Dose & 216 & 68.35 \\
\hline How to use & 246 & 77.85 \\
\hline Frequency & 200 & 63.29 \\
\hline Duration & 183 & 57.91 \\
\hline $\begin{array}{l}\text { Storage of the drug at } \\
\text { home }\end{array}$ & 158 & 50 \\
\hline Yes & 219 & 69.3 \\
\hline No & 57 & 18.0 \\
\hline I don't know & 40 & 12.7 \\
\hline
\end{tabular}




\begin{tabular}{|c|c|c|c|}
\hline \multirow[t]{4}{*}{ 9- From where did you SM? } & Pharmacy & 298 & 94.3 \\
\hline & Street market & 14 & 4.43 \\
\hline & Herbal store & 38 & 12.03 \\
\hline & Relative/friend & 28 & 8.86 \\
\hline \multirow[t]{8}{*}{ 10- Reasons for SM } & To save money & 49 & 15.51 \\
\hline & To save time & 145 & 45.89 \\
\hline & Privacy & 33 & 10.44 \\
\hline & Needed quick relief & 201 & 63.61 \\
\hline & No hospital nearby & 36 & 11.39 \\
\hline & Previous experience & 158 & 50 \\
\hline & $\begin{array}{l}\text { Health problem not } \\
\text { serious }\end{array}$ & 212 & 67.09 \\
\hline & $\begin{array}{l}\text { Embarrassed of } \\
\text { discussing own } \\
\text { symptoms }\end{array}$ & 8 & 2.53 \\
\hline \multirow{2}{*}{$\begin{array}{l}\text { 11- Have you ever experienced a negative side effect after } \\
\text { SM? }\end{array}$} & Yes & 71 & 22.5 \\
\hline & No & 245 & 77.5 \\
\hline \multirow[t]{4}{*}{ If yes } & Drug side effects & 49 & 69.01 \\
\hline & Disease recurrence & 12 & 16.9 \\
\hline & Resistance to drug & 9 & 12.68 \\
\hline & Drug interactions & 8 & 11.27 \\
\hline \multirow[t]{2}{*}{ 12- Do you feel confident with the use of SM? } & Yes & 246 & 77.8 \\
\hline & No & 70 & 22.2 \\
\hline
\end{tabular}

11- Have you ever experienced a negative side effect after SM?

If yes

More than half $(64.56 \%)$ of respondents reported that the most frequent causes for the practice SM were headache followed by cough and the common cold (34.8\%). Other episodes included fever, acne, menstrual problems, body pain and allergies $(31 \%, 28.48 \%, 24.68 \%, 20.89 \%$, and $14.87 \%$, respectively). More than half (64.87\%) of respondents reported that their personal knowledge was the major source of information for the practice of SM. Approximately two-thirds (69.3\%) of respondents knew the potential adverse reactions of the drug. The majority $(94.3 \%)$ of respondents reported that they obtained SM from a pharmacy, and $12 \%$ used SM from herbal stores. 
Two-thirds (67\%) of respondents reported that they self-medicated because of nonseriousness of the illness, followed by quick relief $(63.61 \%)$. Approximately one-quarter $(22.5 \%)$ of respondents reported that they experienced a negative side effect after SM. Approximately $69 \%$ of them reported side effects from the drug. The majority $(77.8 \%)$ of respondents reported that they felt confident about the use of SM.

\section{Discussion}

To our knowledge, this study is the first to assess the knowledge, attitudes and practices of medical and pharmacy students regarding SM at Qassim University. It has demonstrated essential findings. First, this study showed that the majority $(94.6 \%)$ of the students had good knowledge scores. Second, more than half $(58.4 \%)$ of students had agreeable attitudes toward SM. Third, more than half $(63.9 \%)$ of the students had practiced SM in the last 6 months.

SM for minor diseases and nonserious health conditions appears to be a common practice among students. In Saudi Arabia and other countries, the prevalence of SM practice varies widely throughout all demographic groups. A study by Alshahrani reported the highest prevalence of SM practice in Saudi Arabia, whereas Makeen et al., reported the lowest frequency $(98.7 \% \text { and } 11.4 \% \text {, respectively })^{3,14}$. These findings are similar to another study conducted in Saudi Arabia, which found that $64.8 \%$ of medical students practice SM. ${ }^{11}$ Variations in study sample demographics, research methodology, data collection methodologies, and variation in response rates across studies may have resulted in a wide range of prevalence across different regions.

SM appears to be more prevalent among students than in the general population. One study on Ethiopian medical and pharmacy students found a $38.5 \%$ prevalence. ${ }^{15} \mathrm{SM}$ was also reported by $44.8 \%$ of Bahraini medical students, ${ }^{16} 78.6 \%$ of Indian medical students, ${ }^{17}$ and $55.2 \%$ of Egyptian medical students. ${ }^{18}$ SM was reported by $98 \%$ of Palestinian students in another survey. ${ }^{19}$ Two European studies, one on Slovenian students and the other on Serbian students, found frequencies of $92.3 \%$ and $79.9 \%$, respectively. ${ }^{20-21}$ This could be attributable to a variety of factors, including students' greater pharmacological and clinical educations, or better internet access.

Regarding knowledge, $94.6 \%$ of our students had a good level of knowledge about SM. The ratio of pharmacy students who had good knowledge on this issue was significantly higher than that of medical students. This observation is most likely due to differences in educational courses and curricula within these fields. Furthermore, female students had significantly higher knowledge than male students. This finding is similar to a study conducted among pharmacy students in Iran. ${ }^{22}$

With regard to the practice of SM, our results showed that $63.9 \%$ of the pharmacy and medical students of Qassim University who participated in the study had at least one instance of SM during the past 6 months. Adequate knowledge and the nonacute nature of the condition were identified to be the most important reasons for SM. Likewise, two studies conducted in China and Brazil concluded that the most common reason for SM was a nonserious or transient disease ( $45 \%$ and $46 \%$, respectively). ${ }^{23-24}$ In a 
Rwandan study, having a nonserious disease was the most common reason for SM among university students. ${ }^{25}$ Financial and insurance related issues have been reported as other reasons for SM. ${ }^{26}$ Another study found that bad behavior by health care providers, being too far away from a clinic, and low efficacy of prescribed drugs were all used as justifications by university students for $\mathrm{SM}^{27}$

The most widely utilized medications for SM among our students were painkillers and antipyretics $(60 \%)$. Similarly, our findings were in line with the findings of the majority of similar studies. Painkillers $(60 \%)$ and antipyretics were the most commonly used drugs for SM among our students. Likewise, our results were consistent with the findings of most similar studies ${ }^{18,28-29}$. In other studies, NSAIDs ${ }^{24,30}$, antibiotics $24-25,27$, and pain killers ${ }^{27,30}$ were reported as the most common drugs used for SM. In a study conducted in Pakistan, OTC drugs were found to be the most commonly used pharmaceuticals (98.3\%) by medical undergraduate students ${ }^{31}$. The primary reason for using analgesics and antipyretics for SM is that they do not require a medical prescription, plus are easily and quickly available in pharmacies and other general stores nearby. Our study also revealed that very few students anticipated adverse drug reactions, indicating that all students, regardless of study level, have at least basic knowledge of the drugs used for SM.

A large number of students' attitudes toward SM agreed that SM is an important part of self-care. As a result, students should be aware of the dangers of improper medication use, which can lead to drug resistance, toxicity, and increased adverse effects. Despite the fact that the majority of students use SM, they do not recommend it to others. This attitude explains why most students' perceptions of SM change as they gain knowledge during their studies.

A limitation of this study is the use of a survey tool that has not undergone prior reliability and validity testing. In addition, the results of this study cannot be generalized to other populations in the country because knowledge, attitude, and practice (KAP) might be greatly influenced by sociodemographic factors in the population. More studies on SM need to be performed, especially with increasing SM practice in the region.

\section{Conclusions}

In conclusion, medical and pharmacy students' knowledge of SM appears to be good and is significantly higher among pharmacy students than among medical students; SM was highly practiced among these students. Therefore, medical and pharmacy students should be viewed as important contributors to the public health care system, and as future health professionals, they should be properly educated on good pharmacy practices and responsible SM.

\section{List Of Abbreviations}

SM: Self-Medication 
KAP: Knowledge, attitude, and practice

WHO: World Health Organization

OTC: Over-the-counter medication

\section{Declarations}

\section{Ethics approval and consent to participate}

The study was carried out in accordance with Declaration of Helsinki and approved by the Institutional Review Board at Qassim University (no. E-18-0488), Qassim, Saudi Arabia. Informed consent was obtained from all participants of the study

\section{Consent for publication}

Not Applicable

\section{Availability of data and materials}

The datasets used and/or analyzed during the current study are available from the corresponding author on reasonable request.

\section{Competing interests}

The authors have declared no competing interests.

\section{Funding}

There was no funding for this study.

\section{Authors' contributions}

RD and WT were responsible for the conception of the research idea and the study design, data collection, analysis, interpretation, and drafting of the manuscript. All authors read and approved the final manuscript.

\section{Acknowledgments}

We would like to thank all medical and pharmacy students of Qassim University for their volunteering to participate in the study.

\section{References}


1. World Health Organization. Guidelines for the regulatory assessment of medicinal products for use in self-medication. WHO/EDM/QSM/ 00.1, 2000.

2. Pandya RN, Jhaveri KS, Vyas FI, Patel VJ. Prevalence, pattern and perceptions of self-medication in medical students. Int J Basic Clin Pharmacol. 2017;2(3): 275-80.

3. Alshahrani SM, Alavudeen SS, Alakhali KM, Al-Worafi YM, Bahamdan AK, Vigneshwaran E. Selfmedication among king khalid university students, Saudi Arabia. Risk management and healthcare policy. 2019;12:243

4. Jagadeesh K, Chidananda K, Revankar SP, Prasad NS. Study on self- medication among 2nd year medical students. Int J Basic Clin Pharmacol. 2015;4(1):164-7.

5. Seam M, Reza O, Bhatta R, et al. Assessing the perceptions and practice of self-medication among Bangladeshi undergraduate phar- macy students. Pharmacy. 2018;6(1):6. doi:10.3390/pharmacy601 0006

6. Alsous M, Elayeh E, Jalil MA, Alhawmdeh E. Evaluation of self-medication practice among pharmacy students in Jordan. Jordan J Pharm Sci. 2018;11:1.

7. Ramadan M, Eltaweel A, El Nakhal T, et al. Self-medication among undergraduate medical students of alexandria faculty of medicine: where do we stand? Int J Med Students. 2018;6(2):52-55. doi:10.51 95/ijms.2018.41

8. Gelayee DA. Self-medication pattern among social Science University students in Northwest Ethiopia. J Pharm. 2017;2017

9. Abay SM, Amelo W. Assessment of Self-medication practices among medical, pharmacy, health science students in Gondar University, Ethiopia. Journal of Young Pharmacists. 2010 Jul 1;2(3):30610.

10. Saeed MS, Alkhoshaiban AS, Al-Worafi A, Mohammed Y, Long CM. Perception of self-medication among university students in Saudi Arabia. Archives of Pharmacy Practice. 2014 Oct 1;5(4).

11. Aljaouni ME, Hafiz AA, Alalawi HH, Alahmadi GA, AlKhawaja I. Self-medication practice among medical and non-medical students at Taibah University, Madinah, Saudi Arabia. Int J Acad Sci Res. 2015;3(4):54-65.

12. Albusalih FA, Naqvi AA, Ahmad R, Ahmad N. Prevalence of self-medication among students of pharmacy and medicine colleges of a public sector university in Dammam City, Saudi Arabia. Pharmacy. 2017 Sep;5(3):51.

13. Adnan M, Karim S, Khan S, Sabir A, Al-Banagi AR, Jamal QM, Al Wabel N. Evaluation of selfmedication practices and awareness among students in Al Qassim region of Saudi Arabia. Adnan et al., Clin Pharmacol Biopharm. 2015;4:1.

14. Makeen HA, Albarraq AA, Banji OJ, Taymour S, Meraya A, Alqhatani S, et al. Knowledge, attitudes, and practices toward self-medication in a rural population in SouthWestern Saudi Arabia. Saudi J Health Sci. 2019;8(1):54.

15. Abay SM, Amelo W. Assessment of Self-medication practices among medical, pharmacy, health science students in Gondar University, Ethiopia. Journal of Young Pharmacists. 2010 Jul 1;2(3):306- 
10.

16. James H, Handu SS, Al Khaja KA, Otoom S, Sequeira RP. Evaluation of the knowledge, attitude and practice of self-medication among first-year medical students. Med Princ Pract. 2006;15:270-5.

17. Kumar N, Kanchan T, Unnikrishnan B, Rekha T, Mithra P, Kulkarni V, et al. Perceptions and practices of self-medication among medical students in coastal South India. PLoS One. 2013;8:e72247.

18. El Ezz N, Ez-Elarab H. Knowledge, attitude and practice of medical students towards self medication at Ain Shams University, Egypt. J Prev Med Hyg..52:196;2011

19. Sawalha AF. A descriptive study of self-medication practices among Palestinian medical and nonmedical university students. Res Soc Adm Pharm. 2008;4:164-72.

20. Klemenc-Ketis Z, Hladnik Z, Kersnik J. Self-medication among healthcare and non-healthcare students at University of Ljubljana, Slovenia. Med Princ Pract..401-19:395;2010

21. Lukovic JA, Miletic V, Pekmezovic T, Trajkovic G, Ratkovic N, Aleksic D, et al. Self-medication practices and risk factors for self-medication among medical students in Belgrade. Serbia PLoS One. 2014;9:e114644.

22. Hashemzaei M, Afshari M, Koohkan Z, Bazi A, Rezaee R, Tabrizian K. Knowledge, attitude, and practice of pharmacy and medical students regarding self-medication, a study in Zabol University of Medical Sciences; Sistan and Baluchestan province in south-east of Iran. BMC medical education. 2021 Dec;21(1):1-0.

23. Lei $X$, Jiang H, Liu C, Ferrier A, Mugavin J. Self-medication practice and associated factors among residents in Wuhan, China. Int J Environ Res Public Health. 2018;15:68.

24. Gama ASM, Secoli SR. Self-medication among nursing students in the state of Amazonas - Brazil. Rev Gaucha Enferm. 2017;38:e65111.

25. Tuyishimire J, Okoya F, Adebayo AY, Humura F, Lucero-Prisno lii DE. Assessment of self-medication practices with antibiotics among undergraduate university students in Rwanda. Pan Afr Med J..33:307;2019

26. Karimy M, Rezaee-Momtaz M, Tavousi M, Montazeri A, Araban M. Risk factors associated with selfmedication among women in Iran. BMC Public Health..19:1033;2019

27. Esan DT, Fasoro AA. Assessment of self-medication practices and its associated factors among undergraduates of a Private University in Nigeria. J Environ Public Health. 2018;2018:5439079.

28. Gutema GB, Gadisa DA, Kidanemariam ZA, Berhe DF, Berhe AH, Hadera MG, et al. Self-medication practices among health sciences students: the case of Mekelle University. J Appl Pharm Sci..1:183;2011

29. Verma RK, Mohan L, Pandey M. Evaluation of self medication among professional students in North India: proper statutory drug control must be implemented. Evaluation. 2010;3:60-4.

30. Lee $\mathrm{CH}$, Chang FC, Hsu SD, Chi HY, Huang LJ, Yeh MK. Inappropriate self-medication among adolescents and its association with lower medication literacy and substance use. PLoS One. 2017;12:e0189199. 
31. Kanwal ZG, Fatima N, Azhar S, Chohan O, Jabeen M, Yameen MA. Implications of self-medication among medical students-a dilemma. J Pak Med Assoc. 2018;68:1363-7. 